\title{
New challenges
}

\author{
Ales Fajgelj ${ }^{1}$
}

Published online: 9 January 2018

(C) Springer-Verlag GmbH Germany, part of Springer Nature 2018

The invitation letter from Springer regarding the position of Editor-in-Chief of the Accreditation and Quality Assurance (ACQUAL) journal came as a surprise to me. However, the answer was straightforward: 'Without hesitation, I would be willing to continue the work started by Paul De Bièvre, Helmut Günzler, Heiner Korte and Hendrik Emons, all my respected colleagues'. Saying this, the new function, which is starting now, carries a very personal connotation. Having been active in the field of quality assurance in analytical chemistry for more than 35 years now, I have witnessed and have been involved in many developments related to metrology in chemistry, which have taken place in the last few decades. To be mentioned are: inception of CITAC (Cooperation on International Traceability in Chemistry), creation of CCQM (Consultative Committee for Amount of Substance-Metrology in Chemistry and Biology), transformation of ISO Guide 25 to the ISO/IEC 17025 standard enhancing accreditation of laboratories worldwide, accreditation of reference material producers and PT scheme organizers, evolution of approaches to quantification of uncertainty associated with results of chemical measurements, development of concepts related to metrological traceability, as well as strengthening of internal and external quality assurance at industrial and research laboratory level (proficiency testing), but also at top metrological level (CIPM key-comparisons and pilot studies). Paul De Bièvre, Helmut Günzler and Peter Enders must have had some visionary character when they founded ACQUAL in 1996 within the 'Springer family'. Since then, ACQUAL has provided the ultimate platform for publication and discussion on all the above listed developments and has evolved into the main journal for metrology in chemistry. Throughout all these years the focus of the journal has expanded and the inclusion of standardization and metrology in clinical and biological sciences, developments in metrological aspects

\footnotetext{
Ales Fajgelj

acqual.editoraf@gmail.com

1 Vienna, Austria
}

of qualitative analysis gave new dimensions to topics covered by the ACQUAL.

However, to keep the journal constantly interesting for authors and readers is quite a responsibility. Already as a long serving member of the Intercontinental Advisory Board I was involved in discussions about the ACQUAL journal. Now the responsibility will be greater and confronted with various challenges. Let me name some:

- Standardization, metrology, terminology, etc., are largely based on international agreements and consensuses. These might be affected by cultural, educational, economical and other factors and differences. Being employed by the International Atomic Energy Agency (IAEA), a specialized agency within the UN system of organizations, for more than 23 years now, I have had the opportunity to work closely with laboratories from all world regions and to become familiar with their specifics. It is one of my goals to expand the authorship and readership of the ACQUAL journal in general, but specifically to reach out to Arabic countries, Africa, Latin America and parts of Asia not yet well represented in ACQUAL.

- The impact factor of ACQUAL is not high and authors may decide to submit their manuscripts to other, sometimes less suitable journals, due to the fact that impact factors significantly count in certain communities. This is a very complex issue as manuscripts published in ACQUAL normally result from practical applications and developments in calibration or measurement laboratories. They proved to be very useful and followed by laboratories in assuring quality of their daily (routine) work, but do not necessarily result in further publications referencing the respective ACQ$\mathrm{UAL}$ articles. It is therefore one of my priorities to promote ACQUAL at all suitable occasions and through various information platforms.

- In recent years it has become clear that some topics such as method validation, implementation of quality system in laboratories are becoming 'saturated'. It is not always easy to demonstrate the novelty of certain 
submitted manuscripts. I hope that good cooperation between authors, reviewers and editors will be helpful in this sense.

- On the other hand, the approaches for quantification of measurement uncertainty are still not fully harmonized or even fully utilized. New approaches introduced, e.g., Monte Carlo simulations, Bayesian statistics, human errors components, etc., may make the situation for 'field laboratories' even more complex. This is a specific area where I would like to strengthen the interest of authors and readers of ACQUAL journal.

- Metrological traceability of measurement results is quite pronounced in the new ISO/IEC 17025:2017 standard. Nevertheless, there is still a lot to be done to reach a good common understanding and clear requirements for demonstration and reporting of metrological traceability of measurement results, values assigned to reference materials, etc. This is an area where ACQUAL's role is indispensable.

- The last mentioned, but for me one of the most important future challenges is to attract more contributions/submissions to ACQUAL from biological areas, life sciences and qualitative chemical analysis and to address metrological, quality assurance and standardization issues at micro- and nano-measurement levels.

In conclusion I would like to say that I am honoured to be able to continue contributing to the journal Accreditation and Quality Assurance in a new function as Editor-inChief, thus helping the international chemical and biological community in continual improvement efforts and in bridging the differences still existing in the scientific and technical world through the provision of practitioners' reports, discussions and other relevant information published in the Springer ACQUAL journal. I am grateful to Hendrik Emons and Heiner Korte, who have assured their willingness to provide further support and advice from their rich experience accumulated during many years they have served as ACQUAL Editors-in-Chief, and I am looking forward to close cooperation with Adriaan van der Veen, members of the ACQUAL Intercontinental Advisory Board, numerous reviewers, all Springer staff involved in ACQUAL, and of course all the authors of manuscripts submitted to ACQUAL.

\section{Alěs Fajgelj}

Editor-in-Chief 